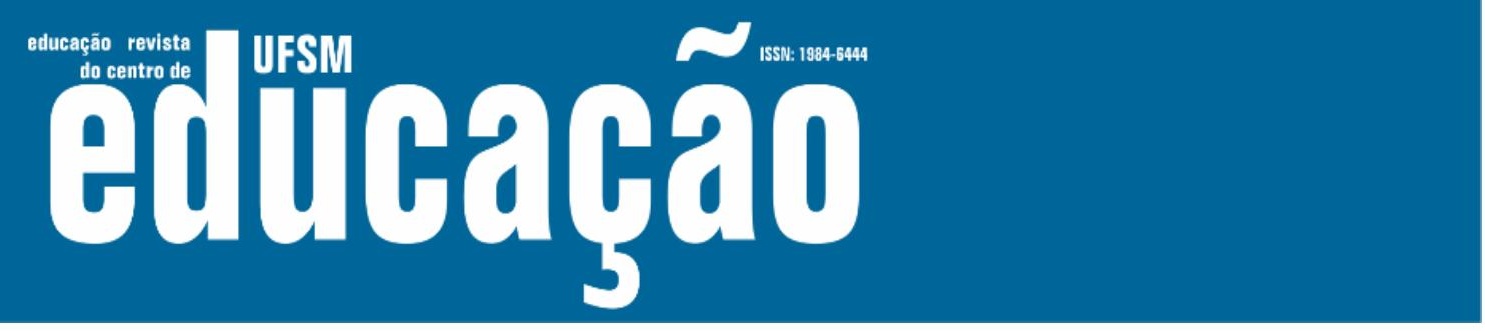

ISSN: 1984-6444 | http://dx.doi.org/10.5902/1984644440743

\title{
Ensino fundamental e as relações de sociabilidades: os adolescentes e a diversidade na escola ${ }^{1}$
}

\author{
Elementary education and the relations of sociabilities: the teenagers \\ and the diversity at school
}

Wilma de Nazaré Baía Coelho

Professora doutora na Universidade Federal do Pará, Belém, Para, Brasil. wilmacoelho@yahoo.com.br - https://orcid.org/0000-0001-8679-809X

Nicelma Josenila Costa de Brito

Pesquisadora na Universidade Federal do Pará, Belém, Para, Brasil. nicelmacbrito@gmail.com - https://orcid.org/0000-0002-7444-4945

Patrícia Simith dos Santos

Graduanda na Universidade Federal do Pará, Belém, Para, Brasil. patricia_simith@hotmail.com - https://orcid.org/0000-0002-6875-0778

Recebido em 07 de janeiro de 2019

Aprovado em 09 de janeiro de 2019

Publicado em 05 de maio de 2021

\section{RESUMO}

Este artigo advém de uma pesquisa realizada com o fomento do Conselho Nacional de Desenvolvimento Científico e Tecnológico (CNPq), que contou com a participação de 175 (cento e setenta e cinco) adolescentes, de duas escolas públicas. Em relação aos objetivos deste texto, priorizamos analisar as relações de sociabilidades estabelecidas entre 111 (cento e onze) estudantes, do $6 . \circ$ ao $9 . .0$ ano, em uma dessas escolas com vínculo ao Ensino Fundamental, em Belém, no Pará. Para a análise pretendida, utilizamos as noções conceituais de violência simbólica, hierarquia e habitus, de Pierre Bourdieu (1996; 2002; 2010), e representação, de Roger Chartier (1982; 1991). No que tange à literatura especializada sobre sociabilidades adolescentes, relações étnico-raciais e relações sociais, adotamos as formulações de Wilma Coelho e Mauro Coelho (2016), Wilma Coelho e Carlos Silva (2015; 2017; 2018; 2019) e Nicelma Soares (2010). As formulações conceituais de Laurence Bardin (2010), Marli André (2003) e Heraldo Vianna (2003) auxiliaram no trato e na sistematização dos dados, na etnografia escolar e nas observações. Os resultados apontam para: a) a centralidade das redes sociais para o estabelecimento, manutenção e rompimento das relações de sociabilidades; b) a necessidade de atenção sobre as redes sociais na experiência escolar - o conteúdo veiculado por meio da experiência online assume lugar secundário em relação às redes de sociabilidades, pois esses estudantes pensam no hoje; c) na percepção 


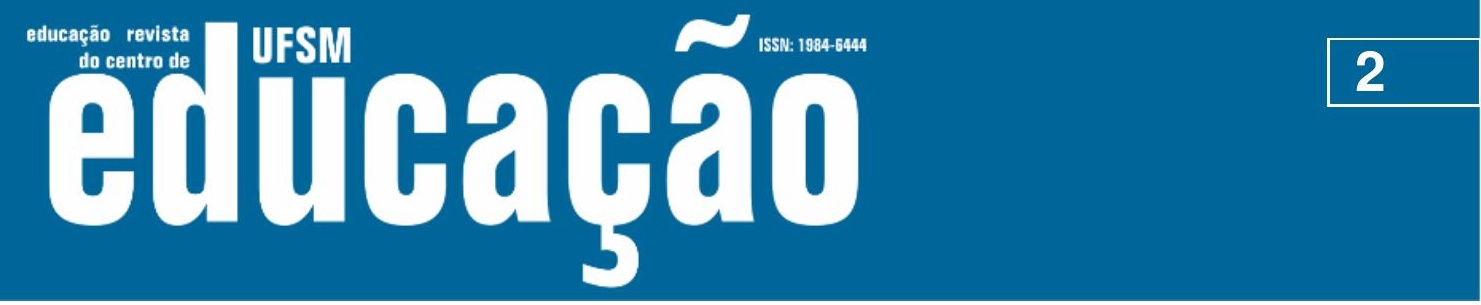

ISSN: 1984-6444 | http://dx.doi.org/10.5902/1984644440743

desses estudantes sobre o espaço escolar, o gosto pelo estudo e tudo que a ele se relaciona figuram como menos relevantes. Recomendamos uma ampliação dos investimentos pedagógicos da escola em relação aos interesses discentes na conformação de suas sociabilidades.

Palavras-chave: Escola; Ensino Fundamental; Sociabilidades adolescentes; Diversidade.

\section{ABSTRACT}

This article is the result of a research carried out with the financial support of the "Conselho Nacional de Desenvolvimento Científico e Tecnológico" (CNPq) (Brazilian National Council for Scientific and Technological Development), which involved 175 (one hundred and seventy-five) adolescents, from two public schools. In relation to the objectives of this text, we prioritize analyzing the sociability relationships established among 111 (one hundred and eleven) students, from the 6th to the 9th grade, in one of these schools linked to Elementary Education, in Belém, Pará, Brazil. In order to carry out the analysis, we used the conceptual notions of symbolic violence, hierarchy and habitus, by Pierre Bourdieu (1996; 2002; 2010), and representation, by Roger Chartier (1982; 1991). Regarding the specialized literature on adolescent sociability, ethnic-racial relations and social relations, we adopted the formulations by Wilma Coelho and Mauro Coelho (2016), Wilma Coelho and Carlos Silva (2015; 2017; 2018; 2019) and Nicelma Soares (2010). The conceptual formulations by Laurence Bardin (2010), Marli André (2003) and Heraldo Vianna (2003) helped in the treatment and systematization of data, school ethnography and observations. The results point out: a) the centrality of social networks for the establishment, development and ruptures of social relationships; b) the need for attention directed to social networks in the school experience - the content conveyed through the online experience plays a secondary role in relation to sociability relationships, because these students think about today; c) according students' perceptions about the school environment, the enjoyment of studying and everything related to it are less relevant. We recommend an expansion of the school's pedagogical investments in relation to students' interests in shaping their sociability.

Keywords: School; Elementary education; Teenagers; Sociabilities; Diversity.

\section{Introdução}

A partir da Constituição Federal de 1988, são propostas reformas estruturais e curriculares que visam um melhor desempenho da educação e do ensino no país. A CF/88 determina que a educação é direito de todos e o estado tem o dever de 


\section{Althaดิão}

ISSN: 1984-6444 | http://dx.doi.org/10.5902/1984644440743

garantir isto, com igualdade de acesso e devidas condições de permanência dos estudantes. Em consonância com tal premissa, a Lei N. 9.394, de 20 de dezembro de 1996 (Lei de Diretrizes e Bases da Educação Nacional - LDB) e as Diretrizes Curriculares Nacionais (DCNs), apresentam orientações gerais para que sejam observadas no Ensino Fundamental de todas as escolas brasileiras a organização, a articulação, o desenvolvimento e avaliação de suas propostas pedagógicas (BRASIL, 2013).

No Brasil, o Ensino Fundamental se conforma como uma das etapas relevantes para a formação básica de crianças e adolescentes, pois constitui modalidade obrigatória da educação brasileira, e tem duração de 09 anos, durante os quais, diversas experiências são vivenciadas por esses agentes no espaço escolar. Tais experiências guardam relevância, não somente para o processo de desenvolvimento cognitivo desses estudantes, como para a constituição de identidade e, por conseguinte, das sociabilidades na escola. Assim, a escola assume relevância nos processos de aprendizagens, na medida em que oportuniza a aquisição naquilo que Young (2007) denomina de conhecimento poderoso, o qual favorece a expansão da escolarização, bem como contribui para a promoção da equidade, sobretudo, em relação a estudantes já socialmente desfavorecidos, dentre os quais, pretos e pardos figuram como um expressivo contingente no panorama das desigualdades, concorrendo para aquilo que Marcelino (2018) denomina o sucesso e o fracasso de estudantes negros.

Ainda sobre o Ensino Fundamental, a Resolução N. 03/2005, do Conselho Nacional de Educação (CNE), define normas para a ampliação deste nível de ensino no país, mediante a obrigatoriedade da matrícula de crianças a partir dos seis anos de idade, medida esta que passou a ser implantada nas instituições escolares a partir do ano de $2010^{2}$ (SAVELI, 2008). Estudos apontam que nos anos finais, diversos fatores comprometedores da aprendizagem despontam na experiência dos estudantes: fracasso escolar, baixo desempenho, reprovações, evasões, abandono, problemas comportamentais os quais demandam atenção por meio da adoção de políticas públicas (MARTURANO e; ELIAS, 2016; D’ABREU e; MARTURANO, 2010). 


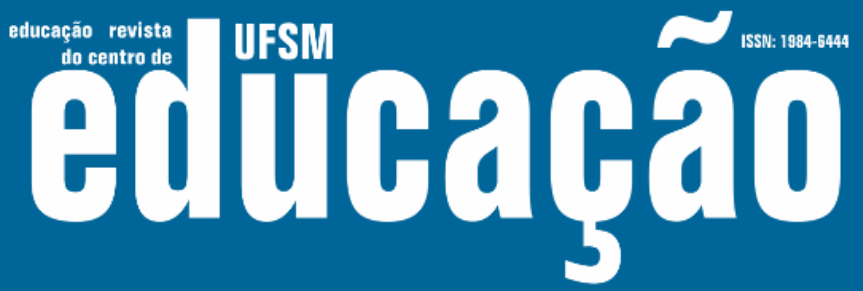

ISSN: 1984-6444 | http://dx.doi.org/10.5902/1984644440743

Para a análise pretendida, nos utilizaremos das noções conceituais de violência simbólica, hierarquia e habitus, em Pierre Bourdieu (1996, 2002, 2010); representação, em Roger Chartier $(1991,1982)$. No que tange à literatura especializada sobre relações sociais, sociabilidades adolescentes e relações étnicoraciais, adotaremos as formulações Wilma Coelho; Mauro Coelho (2016), Wilma Coelho; Carlos Silva (2015; 2017; 2018; 2019), Nicelma Soares (2010). As formulações conceituais de Laurence Bardin (2010), Marli André (2003), Meinerz (2011) e Heraldo Vianna (2003), auxiliaram no trato e sistematização dos dados, etnografia escolar, observações e grupos de discussão realizados na escola. $O$ artigo estrutura-se a partir das seguintes sessões: sobre as dimensões iniciais do estudo; relações de sociabilidades e diversidade na escola sob a ótica dos adolescentes e a discussão sobre a realidade de que o racismo ainda se encontra vivo na escola - impactos nas relações de sociabilidades.

\section{Sobre as dimensões iniciais do estudo}

O recorte que originou o estudo em tela contou com a participação de 111 (cento e onze) estudantes, do $6^{\circ}$ ao $9^{\circ}$ ano, de uma escola pública paraense, no município de Belém. A escola foi selecionada, considerando três aspectos: primeiro, o de integrar o sistema público de ensino; segundo, os Índices de Desenvolvimento da Educação Básica (IDEB) nos últimos anos (a escola apresentou o índice 0,03); o terceiro aspecto consistiu na localização geográfica no entorno da Universidade Federal do Pará, no bairro do Guamá4.

A escola oferta as modalidades de Ensino Fundamental (6을 oㅜ ano), Ensino Médio e Educação de Jovens e Adultos (EJA) em três turnos, e comporta, no Ensino Fundamental, duas turmas de cada ano, as quais totalizam 223 (duzentos e vinte e três) estudantes. Destes, o universo de 111 (cento e onze) estudantes, compôs a amostra de $50 \%$ desse nível de ensino, para reflexão sobre a escola.

Para este estudo, que se constitui uma pesquisa de cunho qualitativo (BOGDAN; BIKLEN, 1994), adotamos procedimentos metodológicos que foram desde a inserção na escola para a realização da observação participante (nas salas 


\section{Autตaดูão}

ISSN: 1984-6444 | http://dx.doi.org/10.5902/1984644440743

de aulas e diversos espaços frequentados pelos estudantes na instituição); aplicação de questionários e o grupo de discussão (MEINERZ, 2011). Tais procedimentos foram acionados objetivando identificar o perfil das relações de sociabilidades estabelecidas entre os adolescentes na escola, com vistas a analisar as percepções destes sobre aquelas relações de sociabilidades ${ }^{5}$, assim como a importância que a escola assume na vida dos mesmos, além do ponto de vista sobre as temáticas e ações voltadas para a diversidade.

Os encaminhamentos iniciais seguiram as seguintes etapas: a) contatos com a direção, coordenadores e coordenadoras da escola, com as finalidades relacionadas aos procedimentos éticos e formais da pesquisa; b) autorização dos pais e responsáveis, por meio de Termo de Consentimento; c) observações, durante 6 (seis) meses em sala e no ambiente escolar (corredores, quadras de esportes, refeitórios e pátios). As observações em sala de aula consideraram as disciplinas de Língua Portuguesa, História, Artes, Estudos Amazônicos e Educação Religiosa - a definição dessas disciplinas relaciona-se ao fato de que nelas, a temática sobre a diversidade assume enfoques distintos; d) aplicação dos questionários, para elaboração do perfil dos estudantes, considerando dimensões pessoais, escolares, socioeconômica e cultural. Além destas, abarcaram dimensões relativas à formação de grupos juvenis, interação na internet, relação com a escola e amizades; e) grupos de discussão, considerando o aprofundamento de questões sondadas inicialmente por outros suportes.

Os instrumentos adotados possibilitaram a identificação qualitativa dos estudantes, a qual conforma um perfil de maioria negra (75\%), com representação etária, em sua maioria, de 16 anos (35\%), e o menor percentual, com a idade de 14 anos (10\%), em um universo de quase $60 \%$ de meninos. Dentre os estudantes, a maioria $(77,5 \%)$ tem casa própria; com um mínimo de 4 (quatro) pessoas morando no mesmo ambiente. Em tais domicílios, quase 70\% possui, no mínimo, 01 (um) aparelho de televisão e acesso à internet. Com 35\% de acesso aos canais de TV a cabo, a maioria (50\%) possui, no mínimo, um aparelho celular. Para a locomoção, $75 \%$ utilizam entre ônibus e outros transportes para deslocamento para a escola. 


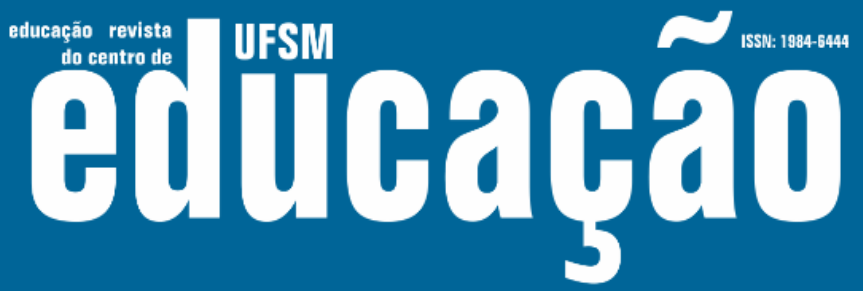

ISSN: 1984-6444 | http://dx.doi.org/10.5902/1984644440743

Explicitados os procedimentos, cenários e agentes que permearam este estudo, na próxima sessão nos deteremos no que dizem os estudantes sobre suas relações de sociabilidades e diversidade.

\section{Relações de sociabilidades e diversidade na escola sob a ótica dos adolescentes}

Convém situarmos a compreensão sobre a qual este estudo se assenta, no tocante as adolescências. A adoção do termo, no plural, subsidia-se pela literatura especializada, a qual tem demonstrado, em estudos como os de Ozella e Aguiar (2008) a multiplicidade de adolescências e a multideterminação que os contextos nos quais se inserem, encaminham a esta experiência. Outra premissa a ser considerada, diz respeito às sociabilidades e diversidade. Coelho e Silva (2015, 2019) ponderam que tais sociabilidades, desenvolvidas no âmbito das dinâmicas escolares, tanto virtuais, quanto presenciais, sofrem o impacto das representações sobre raça, cor, preconceito racial, discriminação e identidade negra.

As Diretrizes Curriculares Nacionais para a Educação das Relações Étnicoraciais encaminham, dentre seus princípios, a crítica e a subversão das representações estereotipadas sobre negros ${ }^{6}$ e outras chamadas minorias. Elas propõem a construção de referências positivas para a educação das relações étnicoraciais (BRASIL, 2004). Compreender a educação das relações étnico-raciais foi, e continua sendo, relevante, especialmente nos espaços formativos de crianças e adolescentes, naquilo que Nilma Lino Gomes (2008) considera como espaços estratégicos para o debate de questões como exclusão, discriminação e marginalização de um segmento social. Entre tais espaços, figura a escola.

A posição estratégica da escola possibilita re-produções de naturalizações, de ações racistas existentes e reproduzidas por parte dos setores sociais. Como microcosmo social o ambiente escolar experimenta a re-produção de parte das estereotipias que circulam na sociedade, de forma mais ampla. Não raras vezes, na escola, o racismo se reveste do que Margarida Knobbe (2005) identificou como o biombo da piada, e Silva e Paludo (2011), como brincadeiras e piadas. Contudo, de 


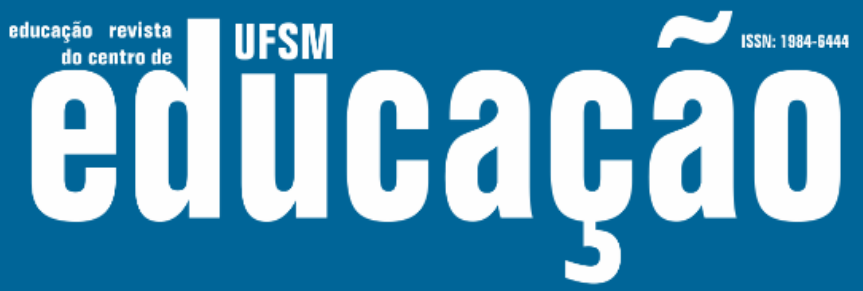

ISSN: 1984-6444 | http://dx.doi.org/10.5902/1984644440743

brincadeira, e de piada, o racismo não tem nada! Portanto, os estudos no interior da escola, como uma parte da literatura especializada já aponta, são pródigos no sentido de identificar o problema, analisar alternativas e encaminhar estratégias em diálogo com os agentes nele envolvidos, uma vez que não se pode intervir no que não se conhece, sob pena de agir, conforme argumento de Wilma Coelho e Mauro Coelho (2008), sob as bases do improviso. Em relação a crianças e adolescentes, é impossível improvisar.

As ações escolares pautadas no improviso, anunciadas por Coelho e Coelho (2008) há mais de uma década, continuam demandando a intervenção conscienciosa proposta por Wilma Coelho (2009). Se considerarmos as relações de sociabilidades engendradas pelos estudantes, esta demanda também responde à chamada. Senão vejamos: Coelho e Coelho (2015) argumentam sobre a potencialização que a atuação da escola assume ao compreender as culturas juvenis. Expressivo contingente dos estudantes (71\%) da escola pesquisada reporta a existência de grupos juvenis naquele ambiente. Compreender as dinâmicas sob as quais se assentam essas sociabilidades representa possibilidade da intervenção conscienciosa, proposta por Wilma Coelho (2009), reduzindo assim, as distâncias entre os objetivos legais e a experiência na escola (COELHO; COELHO, 2015).

Os adolescentes indicam a boa conversa como principal elemento na definição de pessoas para estarem ao lado. Os elementos que seguem na ordem das definições, relacionam-se a comportamentos como não ser falso; gostar de brincar e gostar de estudar, respectivamente. Paradoxalmente, ainda que estejamos falando da escola, os estudantes indicam o gostar de estudar como o comportamento que ocupa a última posição na definição de pessoas para estarem ao lado, nas relações que estabelecem naquele espaço. Os elementos com indicações mais presentes relacionam-se a conversas e comportamentos que as sociabilidades demandam em quaisquer outros ambientes fora da escola. 


\section{N

ISSN: 1984-6444 | http://dx.doi.org/10.5902/1984644440743

Figura 1 - Comportamentos que concorrem, segundo os estudantes, para estar ao lado de alguém na escola

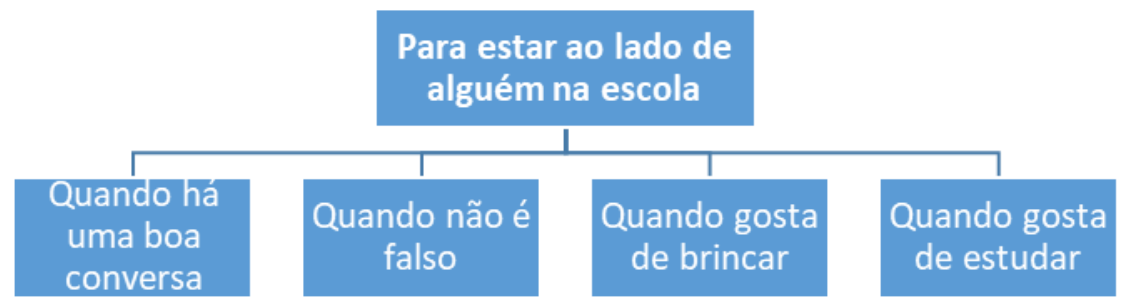

Fonte: Dados produzidos pelas pesquisadoras a partir dos grupos de discussão, 2018.

$\mathrm{Na}$ mesma direção das definições para estarem ao lado dos colegas, as relações de sociabilidades são engendradas por traços como confiança e amizade e por comportamentos como bom humor. A exemplo das definições dos elementos que precisam se apresentar nas pessoas que escolhem ter por perto, as relações de sociabilidades que os estudantes experimentam na escola têm por base elementos que permeiam as relações mais amplas, fora daquele ambiente.

Figura 2 - Elementos pelos quais os estudantes estabelecem relações de sociabilidades na escola

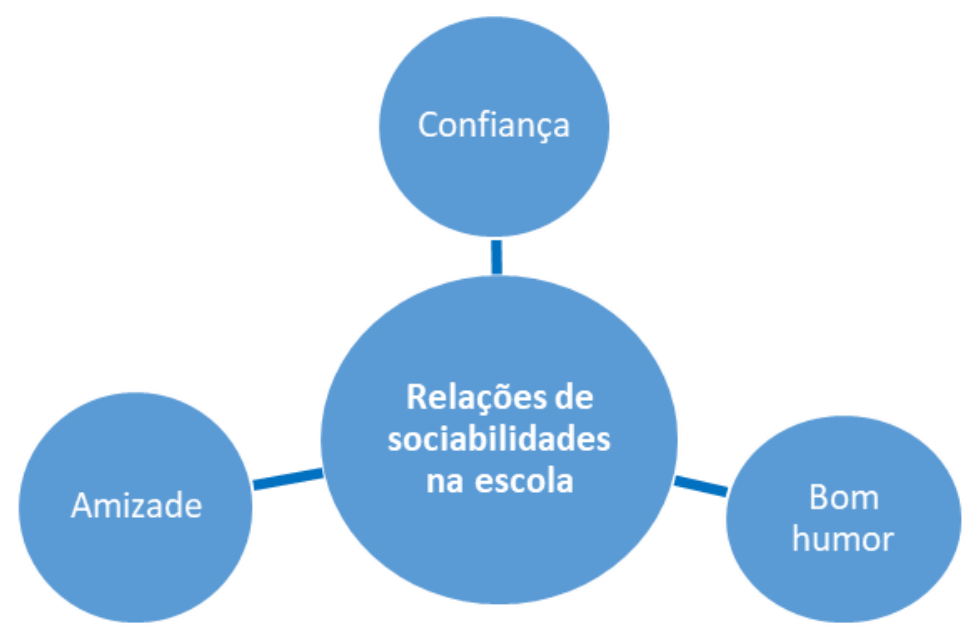

Fonte: Dados produzidos pelas pesquisadoras a partir dos grupos de discussão, 2018. 


\section{Authaดูã}

ISSN: 1984-6444 | http://dx.doi.org/10.5902/1984644440743

Os elementos relacionados ao ambiente escolar se apresentam quando inquirimos sobre aspectos negativos. Na verificação do que não gostam, o preconceito desponta como primeira indicação nos comportamentos rejeitados pelos estudantes. A ele se segue o fato de não gostar de estudar, como segundo elemento de rejeição nas relações na escola. Os dados relativos às rejeições dos estudantes são reiterados, dentre os elementos que concorrem para o afastamento dos colegas: na ordem, são mencionados não gostar de estudar; a ausência de confidencialidade e companheirismo nas relações e a aparência física.

Quadro 1 - Elementos de rejeição nas relações dos adolescentes na escola.

\begin{tabular}{|l|l|}
\hline \multirow{2}{*}{ Não gostam de alguém quando: } & A pessoa é preconceituosa \\
\cline { 2 - 2 } & Não gosta de estudar \\
\cline { 2 - 2 } & Fala mal dos outros \\
\hline \hline \multirow{2}{*}{ Os estudantes se afastam dos colegas quando: } & Não gostam de estudar \\
\cline { 2 - 2 } & Não são confidentes, ou companheiros \\
\cline { 2 - 2 } & Por conta da aparência física \\
\hline
\end{tabular}

Fonte: Dados produzidos pelas pesquisadoras a partir dos grupos de discussão, 2018.

Novamente os elementos indicados nas relações estabelecidas na escola, presentes nas sociabilidades dos adolescentes, afluirão na conformação dos grupos que circulam naquele ambiente. Os aspectos que denotam atenção são aqueles voltados especialmente para dimensões externas à escola: os brincalhões, as meninas, os do fundão, cujas características poderiam ser percebidas em qualquer ambiência social juvenil. A exceção que confere especificidade para a dimensão escolar, percebida pelos próprios, são os nerds, que não desfrutam do "privilégio" de circulação entre todos os grupos, em contraponto com os demais. 


\section{Althaห̧ão}

ISSN: 1984-6444 | http://dx.doi.org/10.5902/1984644440743

aos grupos - moda, maquiagem, música, danças, conquistas amorosas, encontros, desencontros, sucessos, dissabores, dentre outros.

Em relação aos elementos de reiteração e identificação entre os grupos, a despeito da socialização virtual, a demarcação estética nas relações presenciais, assume relevância, mesmo que secundária. Se naquele, eles postam para todos visualizarem e receberem likes (postam fotos juntos no status do Whatsapp, gravam vídeos para serem postados no Instagram, trocam carinhos, consolos e outros mais), nestas, a demarcação se concretiza pelo uso de adereços e vestimentas ${ }^{8}$ comuns ao grupo de pertencimento - chapéus, piercings, pulseiras e brincos coloridos, uniforme customizado, maquiagem, sandálias, mochilas com alças longas e moletom. Além dessas demarcações estéticas, os beijos entre si (independente de gênero) e em algumas situações os socos, xingamentos e pontapés, se constituem ações corriqueiras, entre os adolescentes que podem ocorrer entre estudantes da mesma turma, mas, sobretudo, daqueles que conformam os grupos de adolescentes na escola.

A escola, na compreensão dos estudantes, desconhece a existência do estatuto interno das relações de sociabilidades dos grupos juvenis, embora tenha notícias de sua existência. Quando presentes, as ações advindas dos responsáveis pelo trabalho pedagógico na escola, segundo os estudantes, incidem sobre questões amplas, relacionadas a comportamentos genéricos que impactam aquele ambiente, mas nascem das relações miúdas dessas formações entre os grupos. Contudo, tais ações se distanciam das singularidades que essas formações encerram.

A despeito do protagonismo que assumem nos grupos, os adolescentes colocam em evidência o distanciamento dos mesmos em relação aos gestores da escola, ainda que não haja nenhum sinal de animosidade dos primeiros em relação aos últimos. A percepção deles no que tange ao lugar da escola parece significativa para o redimensionamento desta relação em aberto. 


\section{Authaดูã}

ISSN: 1984-6444 | http://dx.doi.org/10.5902/1984644440743

\section{O racismo ainda se encontra vivo na escola - impactos nas relações de sociabilidades}

A avaliação dos estudantes em relação à escola indica a necessidade de maior proximidade entre esses agentes. Um percentual significativo de estudantes (84\%) considera a relevância de interlocução mais efetiva entre os agentes da escola e eles. Neste sentido, vale a ressalva de Juarez Dayrell (2007) de que a crise deflagrada entre a escola e a juventude prejudica os processos de socialização destes últimos, na medida em que a escola não conhece os meandros dessas relações. A reflexão de Dayrell encontra eco neste estudo e o contrário é verdadeiro, uma vez que tal ausência distancia a escola, na percepção dos problemas havidos dentro dela e, por conseguinte, dos grupos. Dentre os problemas indicados pelos estudantes, o racismo ainda se encontra vivo na escola e impacta as relações de sociabilidades, tanto no interior da escola, quanto fora dela, e vice-versa.

Tal impacto, dentre outras razões, se concretiza naquilo que Mauro Coelho e Wilma Coelho (2015) identificam como incômodo em conviver com a diferença. Em situações de provocações, de xingamentos, ou de deparar-se com "o diferente", os estudantes conferem conotações pejorativas às falas em relação aos colegas:

Tá vendo só, parece até que é preto! (Estudante, 8ํano, pardo, 14 anos Grupos de discussão, 2018)

Esse daí só pode ser autista. (Estudante, 9aano, pardo, 16 anos - Grupos de discussão, 2018)

A forma acionada pelos adolescentes da escola para identificar o outro, a partir de atributos identificados por Goffman (1980) como estigmas indesejáveis uma vez que apresentam incongruências com as determinações criadas para um determinado tipo de indivíduo - em certa medida, denotam uma forma particular de lidar com o diferente. Dentre essas estereotipias, existem outras que são mais acentuadas, concretizadas em forma de racismo. Neste contexto, Wilma Coelho e Mauro Coelho (2015) argumentam sobre a importância da ação pedagógica da escola nas sociabilidades juvenis engendradas neste espaço.

A interlocução havida com os estudantes por ocasião dos grupos de discussão se constitui como um indicativo do quão vivo está o racismo na escola: 


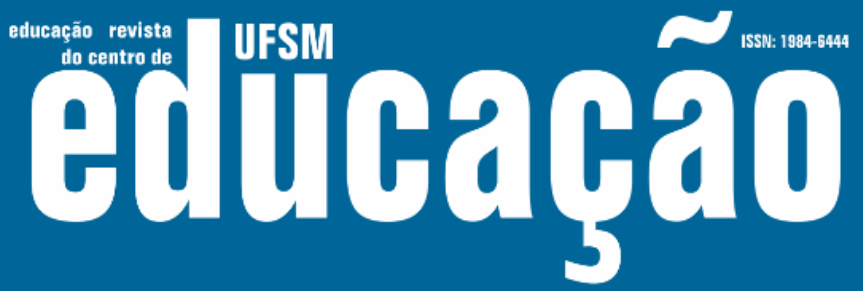

ISSN: 1984-6444 | http://dx.doi.org/10.5902/1984644440743

se refere ao racismo engendrado, não raras vezes, pelos adolescentes-juvenis, na sala aula e, por conseguinte, no ambiente escolar.

A percepção de que ainda somos primitivos encaminha uma experiência que deixa de fora a ideia de comunidade, exclui a diversidade e desconsidera a diferença. A despeito do reconhecimento do quão nocivas as ações racistas se constituem, paradoxalmente os estudantes consideram, em algumas situações, tais práticas como banais, ou como brincadeiras. A educação para a diferença promove uma experiência social demarcada pela diversidade, pela pluralidade e pelo conflito. Neste aspecto, Mauro Coelho (2019) reitera a diferença, como constitutiva da experiência social, que deve ser reconhecida, valorizada e respeitada, tal como definida na legislação educacional para a diversidade (BRASIL, 2004). Assim, a ideia contrária à assertiva do estudante - de ainda sermos primitivos - evoca as atitudes, posturas e valores que eduquem cidadãos quanto à pluralidade étnica e racial, presente em uma sociedade plural.

\section{Considerações finais}

A análise das relações de sociabilidades estabelecidas entre adolescentes, em uma escola da rede pública estadual de Ensino Fundamental de Belém - PA, tendo por base Meinerz (2005), no que se refere aos processos de interação que concretizam as sociabilidades, denotam a construção social atribuída por Coelho e Silva (2018) a este processo. Os dados sinalizam que os estudantes têm nas redes sociais a centralidade da sua atenção, inclusive no estabelecimento e no rompimento das relações de sociabilidades. São estudantes com participação limitada da figura paterna, e quando presentes, o nível de interação se constitui por meio de um interesse em comum - a televisão - mas se distinguem no que nela assistem: enquanto as mães são prevalentes pelas novelas, os pais o são pelos programas esportivos. Os índices de leitura também são similares pela não leitura de livros, nas três categorias, bem como, no tocante a leitura de jornais, pelos pais e filhos, entretanto se distanciam em termos do interesse maior dos filhos; do suporte por meio do qual estes acessam e da sessão de sua preferência (Mundo, para os 


\section{Althaห̧ão}

ISSN: 1984-6444 | http://dx.doi.org/10.5902/1984644440743

filhos, Variedades e Policial, pelos pais). Em relação às mães, embora detenham maior escolarização (Ensino Fundamental e Médio completos), essa formação não concretiza a intensidade da leitura. Esse quadro, de certo modo, se reproduz em relação a não leitura dos filhos, os quais se obrigam a ler, restritamente o exigido pelas atividades escolares.

A centralidade das atenções sobre as redes sociais encaminha as relações estabelecidas entre eles como o foco do interesse na experiência escolar. Tal experiência se pauta menos nos conteúdos produzidos na escola; distante de perspectivas de futuro, da influência docente, mas em função das redes de sociabilidades constituídas naquele espaço. Esses estudantes pensam no hoje. Sob a limitação temporal desta perspectiva, o investimento da escola tem passado ao largo desses interesses. Isso não implica em não-aprendizado. Essas construções podem não se constituir no projetado pela escola em termos de aprendizado, uma vez que estes adolescentes não sinalizam interesse pelo que tem sido projetado para eles; preferem estar nos corredores, refeitório, pátio da escola e nas escadas, em detrimento da sala de aula, e quando lá estão, não raras vezes, estão só de corpo presente, no dizer de Wilma Coelho (2005). As saídas renitentes (tomar água, ir ao banheiro) representam para a maioria, uma estratégia para escapar das aulas sistematicamente. Os encontros com os grupos ocorrem, via de regra, nas áreas externas da escola, daí, as escapadas frequentes das aulas. Em tais encontros, as piadas, a música, a brincadeira, os apelidos, as postagens, as conversas prevalecem entre os adolescentes.

Tais comportamentos parecem corriqueiros nas escolas em distintos espaços geográficos e temporais, com poucas distinções. Contudo, o que se destaca na experiência dos adolescentes que integram este estudo, reside na ordem de relevância do lugar ocupado pela escola para os mesmos: é sempre o último. Esta ordem é precedida por comportamentos, preferências musicais, filmes, brincadeiras e a interação nas redes sociais. O gosto pelo estudo, e tudo que a ele se relaciona, figura como menos relevante, na indicação dos estudantes em relação ao espaço escolar. Tal consideração se concretiza nos dados analisados, sobretudo quando os estudantes assumem que suas relações estabelecidas no espaço escolar não 


\section{تutดaดูão}

ISSN: 1984-6444 | http://dx.doi.org/10.5902/1984644440743

priorizam o gosto pelo estudo. Para esses estudantes a escola se constitui um ambiente transitório para o estabelecimento de relações de sociabilidades presenciais e virtuais, não prioritariamente atinentes ao conteúdo veiculado naquele espaço escolar. Por meio desse estabelecimento de relações de sociabilidades, se fortalecem os grupos constituídos fora da escola, mas que operam cotidianamente também naquele espaço. A menor relevância materializa-se, finalmente, em razão da parca interlocução entre os agentes escolares - leia-se, principalmente, professores e coordenadores - e as demandas desses estudantes no estabelecimento de suas relações de sociabilidades e formação de grupos que circulam no ambiente escolar.

Tais aspectos demandam investimentos - do ponto de vista pedagógico - que aprofundem o que para os estudantes se constitui como o mais representativo em suas experiências na escola: as relações que estabelecem.

Como esse espaço se constitui, praticamente como um espaço de entretenimento, nesse ambiente tudo ocorre de modo espontâneo, por vezes sem a intervenção pedagógica da escola. As manifestações relacionadas ao racismo, não estão fora deste contexto. As representações dos estudantes sobre o racismo, embora o reconheçam como nocivo, são assumidas como banais, ou como brincadeiras. Parece-nos que a crise da escola, sobre a qual fala Dayrell (2007), contribui para o descompasso entre a compreensão do caráter nocivo e a reiterada manifestação do mesmo no ambiente escolar, com sua propagação por meio daquilo que potencialmente tem sido uma maneira de sociabilidade dos estudantes do Ensino Fundamental: as redes sociais. Os adolescentes paraenses, não diferentemente dos cearenses estudados por Luciana Miranda, José Souza Filho e Maité Santiago (2014), encontram nas redes sociais, uma forma de lazer que os congrega. Ainda que as redes sociais assumam relevância, as relações presenciais, fortalecidas nos ambientes externos da escola, assumem, conforme Carla Meinerz (2005), importância nas sociabilidades estabelecidas pelos adolescentes. 


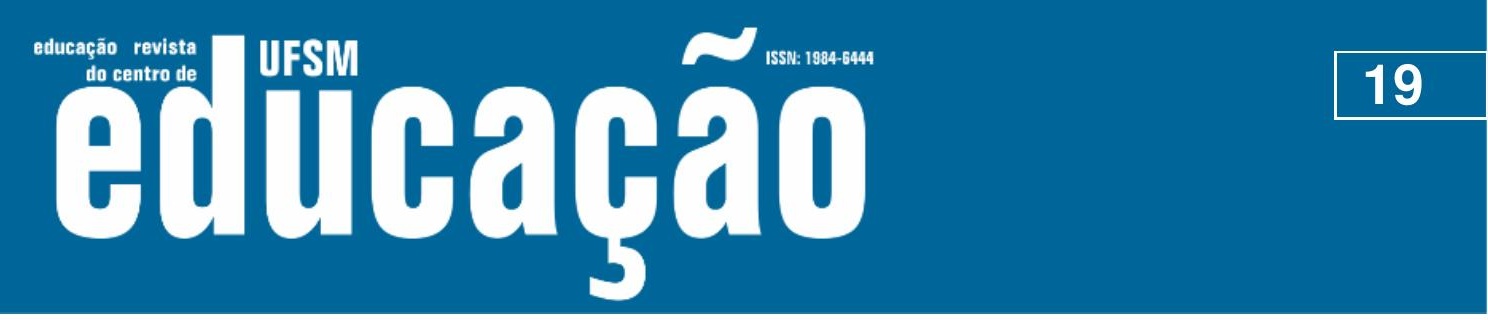

ISSN: 1984-6444 | http://dx.doi.org/10.5902/1984644440743

\section{Referências}

ANDRÉ, Marli Eliza Dalmazo Afonso. Etnografia da Prática Escolar. 9. ed. São Paulo: Papirus, 2003.

BARDIN, Laurence. Análise de conteúdo. 5.ed. Tradução de Luís Antero Reto, Augusto Pinheiro. Lisboa: Edições 70, 2010.

BERGER, Peter Ludwig. LUCKMANN, Thomas. A construção social da realidade: tratado de sociologia do conhecimento. Rio de Janeiro: Editora Vozes, 2004.

BOGDAN, Robert. BIKLEN, Sari Knopp. Investigação qualitativa em Educação: uma introdução à teoria e aos métodos. Coleção Ciências da Educação. Porto, Portugal: Porto Editora, 1994.

BRASIL, Ministério da Educação. Secretaria de Educação Básica. Diretoria de Currículos e Educação Integral. Diretrizes Curriculares Nacionais Gerais da Educação Básica. Brasília: MEC, SEB, DICEI, 2013. Disponível em: http://portal.mec.gov.br/docman/julho-2013-pdf/13677-diretrizes-educacao-basica2013-pdf/file. Acesso em: 10 ago. 2019.

BRASIL, Conselho Nacional de Educação. Resolução N. 3, de 3 de agosto de 2005. Define normas nacionais para a ampliação do Ensino Fundamental para nove anos de duração. Disponível em: http://portal.mec.gov.br/cne/arquivos/pdf/rceb003_05.pdf. Acesso em: 09 jul. 2019.

BRASIL, Diretrizes Curriculares Nacionais para a Educação das Relações Étnico-raciais e para o Ensino da História Afro-brasileira e Africana. Brasília/DF: SECAD/ME, 2004. Disponível em: http://www.acaoeducativa.org.br/fdh/wpcontent/uploads/2012/10/DCN-s-Educacao-das-Relacoes-Etnico-Raciais.pdf

Acesso em: 13 jul. 2019.

BRASIL, Ministério da Educação. Resolução CNE/CEB N. 2, de 7 de abril de 1998. Institui as Diretrizes Curriculares Nacionais para o Ensino Fundamental. Disponível em:

http://www.educacaorc.com.br/media/biblioteca/2020295/resolucaocne_ceb2_98.pdf Acesso em: 09 jul. 2019.

BRASIL, Ministério da Educação. Lei N. 9.394, de 20 de dezembro de 1996. Estabelece as Diretrizes e Bases da Educação Nacional. Disponível em: http://www.planalto.gov.br/ccivil_03/leis//9394.htm. Acesso em: 09 jul. 2019.

BRASIL. Constituição Federal de 1988. Promulgada em 5 de outubro de 1988. Disponível em: http://www.planalto.gov.br/ccivil_03/constituicao/constituição.htm Acesso em: 09 jul. 2019.

BOURDIEU, Pierre Felix. Razões práticas: sobre a teoria da ação. 6. ed. Tradução de Mariza Corrêa. Campinas: Papirus, 1996. 


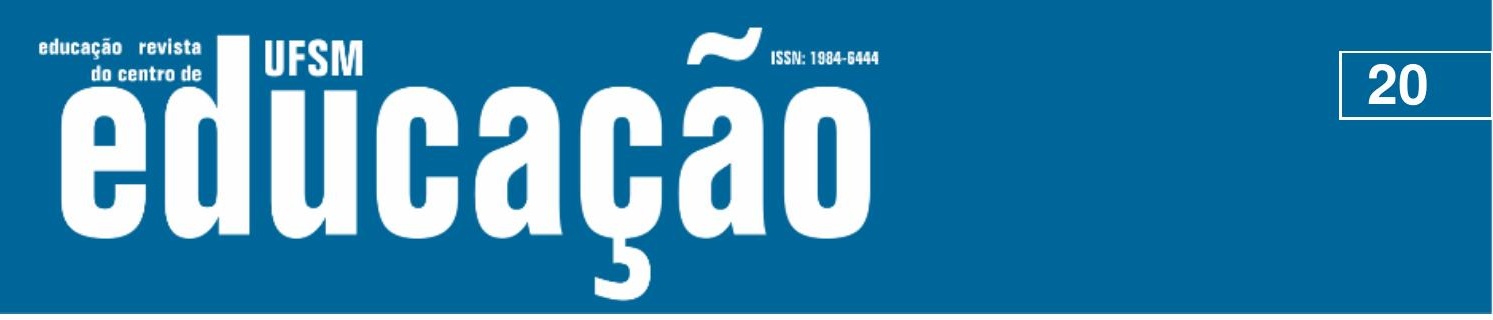

ISSN: 1984-6444 | http://dx.doi.org/10.5902/1984644440743

BOURDIEU, Pierre Felix. As regras da arte: gênese e estrutura de campo literário. Tradução de Maria Lúcia Machado. São Paulo: Companhia das Letras, 2002.

BOURDIEU, Pierre Felix. O poder simbólico. Tradução de Fernando Tomaz. 14. ed. Rio de Janeiro: Bertrand Brasil, 2010.

CASTRO, Marina Ramos Neves de; CASTRO, Fábio Fonseca de. No emaranhado do Guamá: trajetos etnográficos numa feira de Belém. Ponto Urbe [Online], n. 20, 2017. Disponível em: http://journals.openedition.org/pontourbe/3404 ; DOI : 10.4000/pontourbe.3404. Acesso em: 15 jun. 2019.

CAVALLEIRO, Eliane. (Org). Racismo e anti-racismo na educação: repensando nossa escola. São Paulo: Summus, 2001.

CHARTIER, Roger. O Mundo como Representação. Estudos Avançados, São Paulo, v. 5, n. 11, jan./abr.1991, p.173 a 191. Disponível em: http://www.scielo.br/scielo.php?script=sci_arttext\&pid=S0103-40141991000100010. Acesso em: 15 de jun.2019.

CHARTIER, Roger. A história cultural entre práticas e representações. Tradução de Maria Manuela Galhardo. Lisboa: Difusão Editorial, 1982.

COELHO, Wilma de Nazaré Baía. A cor ausente: um estudo sobre a presença do negro na formação de professores - 1970-1989. 2. ed. Belo Horizonte: Mazza, 2009.

COELHO, Wilma de Nazaré Baia. A cor ausente: um estudo sobre a presença do negro na formação de professores - Pará, 1970 1989. Tese (Doutorado em Educação) - Universidade Federal do Rio Grande do Norte, Natal, 2005.

COELHO, Wilma de Nazaré Baía; SOARES, Nicelma Josenila Brito. Pertencimento racial e relações sociais estabelecidas no espaço escolar. Instrumento: Revista de Estudos e Pesquisas Educacionais. Juiz de Fora, v. 13, n. 1, 2011. Disponível em: https://periodicos.ufjf.br/index.php/revistainstrumento/article/view/18711. Acesso em: 05 jul. 2019.

COELHO, Wilma de Nazaré Baía; COELHO, Mauro Cezar. Preconceito e discriminação para além das salas de aula: sociabilidades e cultura juvenil no ambiente escolar. In: COELHO, Wilma de Nazaré Baía; MULLER, Tânia Maria Pedroso; SILVA, Carlos Aldemir Farias da (Orgs.). Formação de professores, livro didático e a Escola Básica. São Paulo: Editora Livraria da Física, 2016, p. 15-44.

COELHO, Wilma de Nazaré Baia; COELHO, Mauro Cezar. Preconceito e discriminação para além das salas de aula: sociabilidades e cultura juvenil no ambiente escolar. Revista do Instituto de Estudos Brasileiros, v. 62, p. 32-53, 2015. Disponível em: http://www.scielo.br/pdf/rieb/n62/2316-901X-rieb-62-00032.pdf. Acesso em 05 jul. 2019. 


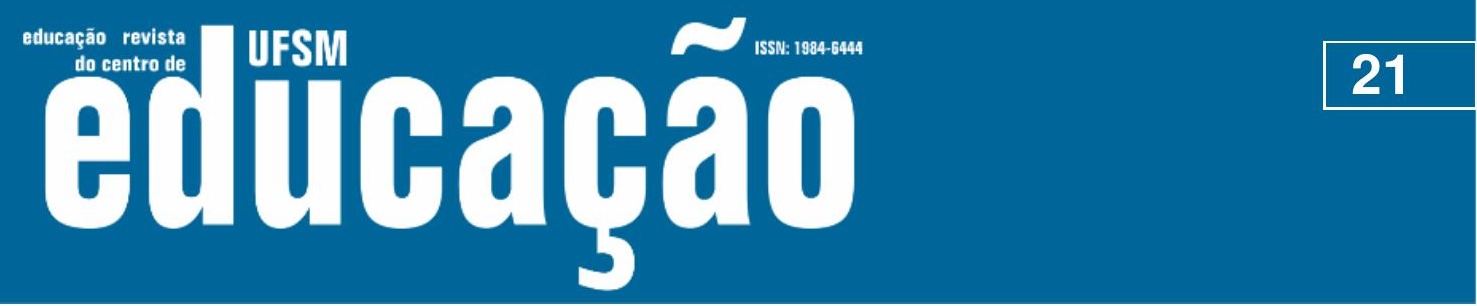

ISSN: 1984-6444 | http://dx.doi.org/10.5902/1984644440743

COELHO, Wilma de Nazaré Baía; COELHO, Mauro Cezar. O improviso em sala de aula: a prática docente em perspectiva. In: COELHO, Wilma de Nazaré Baía; COELHO, Mauro Cezar (Orgs.). Raça, cor e diferença: a escola e a diversidade. Belo Horizonte: Mazza, 2008, p. $104-123$.

COELHO, Wilma de Nazaré Baía; SILVA, Carlos Aldemir Farias. Preconceito, discriminação e sociabilidades na escola. Educere et Educare, v.10, n.20, p.687705, 2015.2 Disponível em: https://www.academia.edu/17712366/PRECONCEITO_DISCRIMINA\%C3\%87\%C3\% 830_E_SOCIABILIDADES_NA_ESCOLA_-

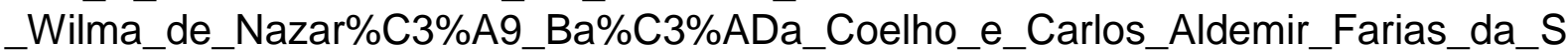
ilva. Acesso em: 10 jul. 2019.

COELHO, Wilma de Nazaré Baía; SILVA, Carlos Aldemir Farias da. Grupos e relações de sociabilidades entre adolescentes no ensino médio: hierarquia e cor. Teoria e prática da educação. v. 20, p. 101-115, 2017. Disponível em: https://www.academia.edu/38164699/GRUPOS_E_RELA\%C3\%87\%C3\%95ES_DE SOCIABILIDADES_ENTRE_ADOLESCENTES_NO_ENSINO_M\%C3\%89DIO_HIE $\bar{R}$ ARQUIA E COR -

WILMA_DE_NAZ̄AR\%C3\%89_BA\%C3\%8DA_COELHO_E_CARLOS_ALDEMIR_F ARIAS DA SILVA. Acesso em: 05 out. 2019.

COELHO, Wilma de Nazaré Baía; SILVA, Carlos Aldemir Farias. Grupos de adolescentes-juvenis no Ensino Médio: sociabilidades, preconceito e discriminação. In: COELHO, Wilma de Nazaré Baía; COELHO, Mauro Cezar (Orgs.) Debates interdisciplinares sobre diversidade e educação. São Paulo: Editora Livraria da Física, 2018.

COELHO, Wilma de Nazaré Baía; SILVA, Carlos Aldemir Farias da. Sociabilidade e discriminação entre grupos de adolescentes-juvenis no Ensino Médio. Educação Unisinos, n.23, v. 2, p. 225-241, abril-junho, 2019. Disponível em: http://ufpa.academia.edu/WilmadeNazar\%C3\%A9Ba\%C3\%ADaCoelho. Acesso em: 08 jul. 2019.

COELHO, Mauro Cezar. Diferença e semelhança. In: FERREIRA, Marieta de Moraes; OLIVEIRA, Margarida Maria Dias (Coord.). Dicionário de Ensino de História. Rio de Janeiro: FGV Editora, 2019, p. 85-90.

D'ABREU, Lylla Cysne Frota; MARTURANO, Edna Maria. Associação entre comportamentos externalizantes e baixo desempenho escolar: uma revisão de estudos prospectivos e longitudinais. Estudos de Psicologia, Natal, n.15, v.1, p.4351, 2010. Disponível em: http://www.scielo.br/scielo.php?pid=S1413294X2010000100006\&script=sci_abstract\&tlng=pt . Acesso em: 09 jul. 2019.

DAYRELL, Juarez. O rap e o funk na socialização da juventude. Educação e Pesquisa, São Paulo, v.28, n.1, p. 117-136, jan./jun. 2002. Disponível em: http://www.scielo.br/pdf/ep/v28n1/11660.pdf. Acesso em: 08 jul. 2019. 


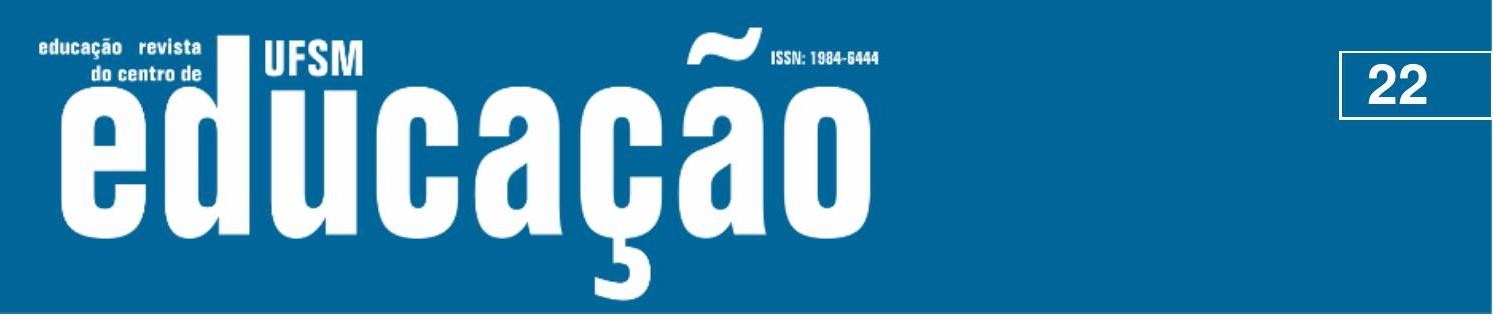

ISSN: 1984-6444 | http://dx.doi.org/10.5902/1984644440743

DAYRELL, Juarez. A escola "faz" as juventudes? Reflexões em torno da socialização juvenil. Educ. Soc., Campinas, v. 28, n. 100 - Especial, p. 1105-1128, out. 2007. Disponível em: http://www.scielo.br/pdf/es/v28n100/a2228100. Acesso em: 09 jul. 2019.

DIAS, Adelaide; OLIVEIRA, João Tiago; MOREIRA, Paulo Alexandre Soares; ROCHA, Leonel. Percepção dos alunos acerca das estratégias de promoção do sucesso educativo e envolvimento com a escola. Estudos de Psicologia, Campinas, n.32, v. 2, p.187-199, 2015. Disponível em: https://psycnet.apa.org/record/2016-10971-004. Acesso em: 09 jul. 2019.

ESSED, P. Understanding everyday racism: interdisciplinary theory. Londres: Sage, 1991.

FERNANDES, Luana de Mendonça; LEME, Vanessa Barbosa Romera; ELIAS, Luciana Carla dos Santos; SOARES, Adriana Benevides. Preditores do Desempenho Escolar ao final do Ensino Fundamental: histórico de reprovação, habilidades sociais e apoio social. Temas em Psicologia, v. 26, n. 1, p.215-228, 2018.

Disponível

em: http://pepsic.bvsalud.org/scielo.php?script=sci_arttext\&pid=S1413-

389X2018000100009. Acesso em: 09 jul. 2019.

GOFFMAN, Erving. Estigma - notas sobre a manipulação da identidade deteriorada. Rio de Janeiro: Zahar, 1980

GOMES, Nilma Lino (Org.). Práticas pedagógicas de trabalho com relações étnico-raciais na escola na perspectiva da Lei 10.639/2003. Brasília: MEC; Unesco, 2012;

GOMES, Nilma Lino. Descolonizar os currículos: um desafio para as pesquisas que articulem a diversidade étnico-racial e a formação de professores. In: Trajetórias e processos de ensinar e aprender: sujeitos, currículos e culturas - ENDIPE, 14, 2008; Porto Alegre, Anais... Porto Alegre, Edipucrs, 2008.

KNOBBE, Margarida Maria. História extra-oficial: como os negros do Brasil ainda não conquistaram a liberdade. Problemas Brasileiros, n. 371, p. 18-23, 2005. Disponível

em: https://www.sescsp.org.br/online/artigo/2861_HISTORIA+EXTRAOFICIAL. Acesso em: 07 jul. 2019.

MARTURANO, Edna Maria; ELIAS, Luciana Carla dos Santos. Família, dificuldades no aprendizado e problemas de comportamento em escolares. Educar em Revista, n.59, p.123-139, 2016. Disponível em: http://www.scielo.br/pdf/er/n59/1984-0411-er59-00123.pdf. Acesso em: 09 jul. 2019. 


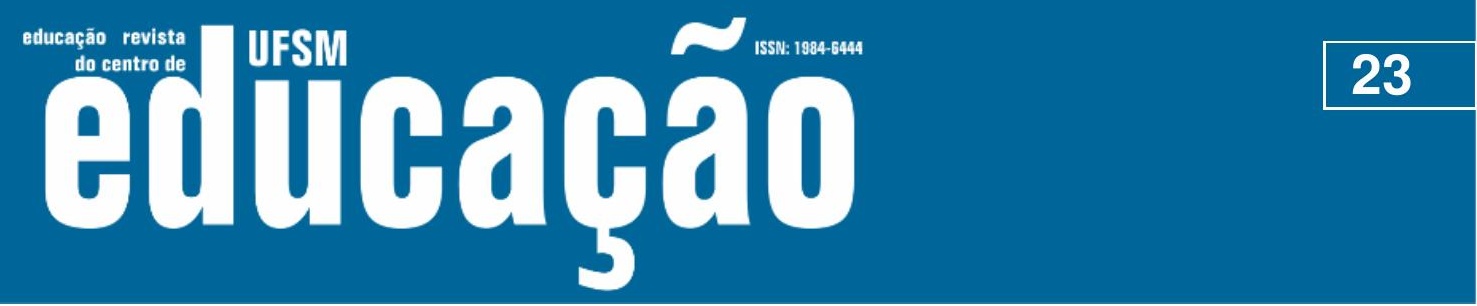

ISSN: 1984-6444 | http://dx.doi.org/10.5902/1984644440743

MARCELINO, Sandra. Escola, racismo e desempenho escolar: o rompimento da profecia auto realizadora do fracasso a partir do relato de três jovens negros. Revista Ensaios e Pesquisa em Educação e Cultura. v. 5, n. 2, p. 104-117, 2018. Disponível

em: http://www.ufrrj.br/SEER/index.php?journal=REPECULT\&page=article\&op=view\&pat h\%5B\%5D=4082 Acesso em: 10 out. 2019.

MEINERZ, Carla Beatriz. Adolescente no pátio, outra maneira de viver a escola. Um estudo sobre sociabilidade a partir da inserção escolar na periferia urbana. Tese (Doutorado em Educação) Programa de Pós-Graduação em Educação - Faculdade de Educação - Universidade Federal do Rio Grande do Sul, 2005.

MEINERZ, Carla Beatriz. Grupos de Discussão: uma opção metodológica na pesquisa em educação. Educação e Realidade, Porto Alegre, v. 36, n. 2, p. 485504, maio-ago. 2011. Disponível em: https://seer.ufrgs.br/educacaoerealidade/article/view/16957. Acesso em: 7 jun. 2019.

MIRANDA, Luciana Lobo; SOUZA FILHO, José Alves de; SANTIAGO, Maité Vicente. A relação lazer e mídia entre adolescentes e jovens de escolas públicas em Fortaleza/CE. Psicol. Argum. Curitiba, v. 32, n. 79, p. 29-43, Supl 1., 2014. Disponível em: http://www.repositorio.ufc.br/handle/riufc/21664 Acesso em: 7 jun. 2019.

MUNANGA, Kabengele (Org). Superando o racismo na escola. 2. ed. Brasília: Ministério da Educação e Cultura; Secretaria de Educação Continuada, Alfabetização e Diversidade, 2005

NADAL, Carla Marlise Silva. A resiliência ao longo da vida de afro descendentes. Dissertação (Mestrado em Educação) - Faculdade de Educação, Pontifícia Universidade Católica - RS, 2007.

OZELLA, Sergio; AGUIAR, Wanda Maria Junqueira de. Desmistificando a concepção de adolescência. Cadernos de Pesquisa, v. 38, n. 133, p. 97-125, jan./abr. 2008. Disponível em: http://www.scielo.br/scielo.php?pid=S010015742008000100005\&script=sci_abstract\&tlng=pt. Acesso em: 15 set. 2019.

PAIXÃO, Marcelo. A dialética do bom aluno: relações raciais e o sistema educacional brasileiro. Rio de Janeiro: Editora FGV, 2008.

ROCHA, Luiz Carlos Paixão. Política Educacional e a Lei 10.639/03: uma reflexão sobre a necessidade de superação de mecanismos ideológicos legitimadores do quando de desigualdades raciais e sociais na sociedade brasileira. In: COSTA, Hilton; SILVA, Paulo Vinicius Baptista (Orgs.). Notas de história e cultura afrobrasileira. Editora UEPG: Ponta Grossa, 2011. 


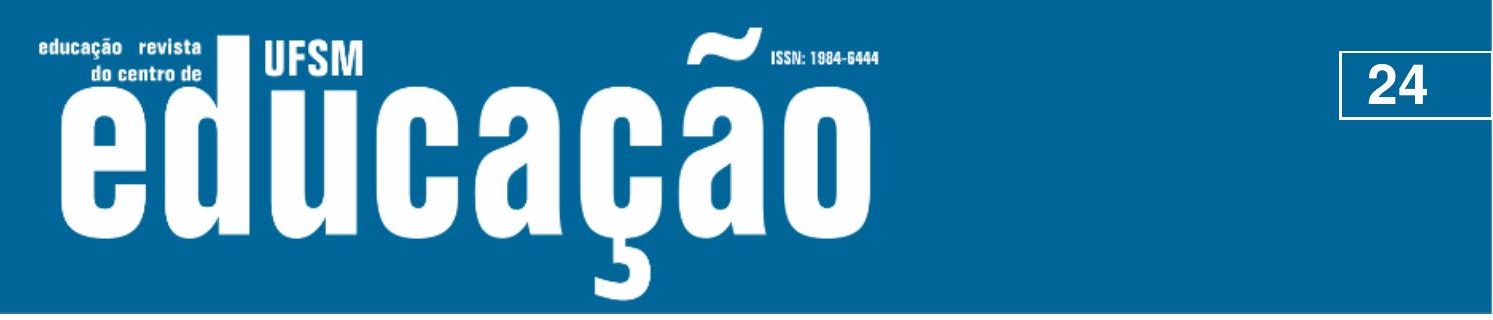

ISSN: 1984-6444 | http://dx.doi.org/10.5902/1984644440743

SAVELI, Esméria de Lourdes. Ensino fundamental de nove anos: bases legais de sua implantação. Práxis Educativa, Ponta Grossa/ PR, v. 3, n. 1, p. 67 - 72, 2008. Disponível em: https://www.researchgate.net/publication/26634895_Ensino_fundamental_de_nove_ anos_bases_legais_de_sua_implantacao. Acesso em: 10 set. 2019.

SILVA, Flávia Carolina da; PALUDO, Karina Inês. Racismo implícito: um olhar para a educação infantil. Revista África e Africanidades, ano IV, n.14/15, 2011. Disponível em: http://www.africanidades.com.br/documentos/14152011-19.pdf. Acesso em: 08 jul.2019.

SILVA JR., Hédio. Discriminação racial nas escolas: entre a entre a lei e as práticas sociais. Brasília: UNESCO, 2002.

SILVA, Petronilha Beatriz Gonçalves e. Crianças negras entre a assimilação e a negritude. Revista Eletrônica de Educação, v. 9, n. 2, p. 161-187, 2015. Disponível em: http://www.reveduc.ufscar.br/index.php/reveduc/article/view/1137. Acesso em: 13 set. 2019.

SISS, Ahyas; OLIVEIRA, Iolanda. Trinta anos de Anped, as pesquisas sobre a educação dos afro-brasileiros e o GT 21: marcas de uma trajetória. In: REUNIÃO ANUAL DA ANPED, GT 21 - Trabalhos Encomendados. 30. 2007, Caxambu, Anais...Caxambu: ANPED, 2007. Disponível em: http://www.anped.org.br/sites/default/files/trabalho_encomendado_gt21-_ahyas__int_pdf. Acesso em: 13 set. 2019.

SOARES, Nicelma Josenila Brito. Relações sociais na escola: representações de alunos negros sobre as relações que estabelecem no espaço escolar. Dissertação (Mestrado em Educação). Universidade Federal do Pará. Instituto de Ciências da Educação. 2010.

TOMÉ, Gina; MATOS, Margarida Gaspar. Relação positiva com grupo de pares na adolescência. In: MATOS, Margarida Gaspar de; TOMÉ, Gina (Eds.), Aventura Social: promoção de competências e do capital social para um empreendedorismo com saúde na escola e na comunidade. São Paulo, SP: Moderna, 2012. p. 111-125

VIANNA, Heraldo Marelin. Pesquisa em educação: a observação. Brasília: Plano Editor, v.5, 2003.

YOUNG, Michael. Para que servem as escolas? Educ. Soc., Campinas, v. 28, n. 101, p. 1287-1302, set./dez, 2007. Disponível em: http://www.scielo.br/pdf/es/v28n101/a0228101.pdf. Acesso em: 09 out. 2019.

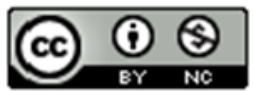

This work is licensed under a Creative Commons Attribution-NonCommercial 4.0 International (CC BY-NC 4.0) 


\section{N

ISSN: 1984-6444 | http://dx.doi.org/10.5902/1984644440743

\section{Notas}

1 Este artigo advém de pesquisa financiada pelo Conselho Nacional de Desenvolvimento Científico e Tecnológico (CNPq).

2 "Essa política educacional implantada no Brasil se constitui em um instrumento legítimo para dar a todas as crianças, independente da classe social, a oportunidade de usufruir do direito de frequentar mais cedo a escola" (SAVELI, 2008, p.68).

${ }^{3}$ O IDEB é calculado com base no desenvolvimento dos estudantes na prova Brasil, realizada no ano de 2017. Fonte: www.qedu.org.br.

${ }^{4}$ O Guamá constitui os bairros mais populosos de Belém. Seu nome é uma referência à sua localização geográfica: está situado às margens do Rio Guamá. De acordo com Castro e Castro (2019), este bairro popular, localizado na zona periférica, consolidou-se em meados do século XIX, com a implantação de uma linha de bonde, e atualmente se conforma, dentre suas muitas características, por ser um bairro estrondoso, a partir de estudo realizado pelos autores na feira que atende os moradores daquela área.

5 A socialização é um processo presente em meio às práticas escolares, assim como as relações sociais, as desigualdades, diferenças étnicas, de gênero e etc. (COELHO e COELHO, 2015).

${ }^{6}$ Sob os impactos destas estereotipias, Rocha (2011) reitera o combate veemente das representações que subdimensionam a imagem do negro na sociedade brasileira.

${ }^{7}$ Garena Free Fire é um jogo eletrônico de acesso on-line. Disponível em aparelhos Android e IOS, que tem por intuito o extermínio de um maior número possível de pessoas.

${ }^{8}$ Juarez Dayrell (2002) menciona que a escolha de uma determinada vestimenta para definir uma característica, constitui-se em uma "complexa trama", que demarca um contexto social e expressa as subjetividades dos estudantes. 